\title{
Bovine Ehrlichiosis Prevalence: A Systematic Review and Meta-Analysis of Molecular Studies
}

\author{
D. Katterine Bonilla-Aldana, ${ }^{1,2,3,4}$ Keidenis Quintero-Rada ${ }^{3}$, Juan Pablo Montoya-Posada ${ }^{3}$, Diego Soler-Tovar ${ }^{4,5}$, \\ Paola Barato ${ }^{4,6}$, Kovy Arteaga-Livias ${ }^{7,8}$, Lysien I. Zambrano ${ }^{4,9}$, Álvaro A. Faccini-Martínez ${ }^{2,4,10}$, and Alfonso J. \\ Rodriguez-Morales $^{2,4,7,11} *$
}

${ }^{I}$ Semillero de Investigación en Zoonosis (SIZOO), Grupo de Investigación BIOECOS, Fundación Universitaria Autónoma de las Américas, Pereira, Risaralda, Colombia

${ }^{2}$ Committee on Tropical Medicine, Zoonoses and Travel Medicine, Asociacion Colombiana de Infectologia, Colombia

${ }^{3}$ Faculty of Veterinary Medicine and Zootechnics, Fundación Universitaria Autónoma de las Américas, Pereira, Risaralda, Colombia

${ }^{4}$ Red Colombiana de Enfermedades Transmitidas por Garrapatas en Pequeños Animales (RECEPA) - Colombian Network of Tick-Borne Diseases in Small Animals (RECEPA), Pereira, Risaralda, Colombia

${ }^{5}$ Epidemiology and Public Health Group, School of Agricultural Sciences, Universidad de La Salle, Bogota, DC, Colombia

${ }^{6}$ Corporación Patología Veterinaria (Corpavet), MolecularVet SAS, Bogotá, Colombia

${ }^{7}$ Master in Clinical Epidemiology and Biostatistics, Universidad Cientifica del Sur, Lima, Peru

${ }^{8}$ Faculty of Medicine, Universidad Nacional Hermilio Valdizán, Huánuco, Peru

${ }^{9}$ Departments of Physiological and Morphological Sciences, School of Medical, Sciences, Universidad Nacional Autónoma de Honduras (UNAH), Tegucigalpa, Honduras

${ }^{10}$ Department of Pathology, University of Texas Medical Branch, Galveston, TX, USA

${ }^{11}$ Grupo de Investigación Biomedicina, Faculty of Medicine, Fundación Universitaria Autónoma de las Américas, Pereira, Risaralda, Colombia

*Corresponding authors' Email: arodriguezm@utp.edu.co; (D) ORCiD: 0000-0001-9773-2192

\begin{abstract}
While some Ehrlichia species, such as E. ruminantium and E. minasensis, are not popular even among veterinarians, they can infect cattle. The current study aimed to review studies on Ehrlichia spp. to evaluate its worldwide molecular prevalence, given the lack of information about bovine ehrlichiosis and the lack of previous systematic reviews and meta-analyses on this subject. In order to determine the molecular prevalence of Ehrlichia spp. in cattle, a systematic review of the literature was conducted in three databases. A meta-analysis with a random-effects model was performed to calculate the pooled prevalence with $95 \%$ confidence intervals $(95 \% \mathrm{CI}$ ) and measures of heterogeneity were reported. Subgroup analyses were performed in terms of Ehrlichia species, country, and regions. The literature search yielded 1051 papers until August 1, 2019, with 71 studies entirely eligible for review. The pooled molecular prevalence for Ehrlichia at the individual level $(\mathrm{N}=6232)$ was $2.3 \%$ (95\% CI: 1.7-2.9\%) with the highest value of $82.4 \%$. Studies identified the highest pooled molecular prevalence of $6.6 \%$ (95\% CI: $0.6-12.7 \%$ ) for E. canis, followed by E. ruminantium $(\mathrm{n}=4695,75.33 \%) 52$ studies, with $1.7 \%$ (95\% CI: $1.1-2.3 \%)$ and $E$. chaffeensis with $1.5 \%$ (95\% CI: $0.0-0.3 \%$ ). Moreover, the obtained result was indicative of only one study addressing E. minasensis. As the findings suggested, heartwater (E. ruminantium infection) is a notifiable disease of domestic and wild ruminants, recorded by the World Organization for Animal Health. There is a possible risk of endemic heartwater in the Americas due to the climatic features. Furthermore, E. minasensis, E. chaffeensis, and E. canis were observed in cattle although the two last species could be a molecular misidentification with regard to their phylogenetic relationships with E. minasensis.
\end{abstract}

Keywords: Bacteria, Bovine, Ehrlichia, Systematic review, Tick-borne

\section{INTRODUCTION}

Ehrlichia species, belonging to the family Anaplasmataceae, can infect cattle (Anifowose et al., 2020; Fargnoli et al., 2020) although some of which, including E. ruminantium and E. minasensis, are not well-known species even among veterinarians (Hector et al., 2019). Bovine ehrlichiosis is manifested by fever without a pattern, ears drooping, turning, and lymphadenitis. In some studies, high mortality has been reported within a few hours in the peri-acute form of the disease, within 36-48 hours in the acute form of the disease, which is usually associated with subclinical infection in the occasional report of severe forms (Stewart, 1992).

Given the lack of previous systematic reviews and meta-analysis about bovine ehrlichiosis, the current study aimed to collect studies addressing Ehrlichia spp. to assess its molecular prevalence worldwide with regard to the available public health reports and observational studies. Moreover, the present review was set to address the prevalence of ehrlichiosis in terms of species, countries, and continents. 


\section{MATERIAL AND METHODS}

\section{Protocol and registration}

The employed protocol followed the recommendations established by the Preferred Reporting Items for Systematic Reviews and Meta-Analyses (PRISMA) statement (Moher et al., 2009).

\section{Eligibility criteria}

This systematic review was conducted on published peer-reviewed articles that reported Ehrlichia species in bovines. Diagnostic methods included only molecular methods because there is a lack of good studies using an appropriate serological test. Serological tests for ehrlichiosis have a limited sensibility and specificity since it is difficult to appropriately discriminate the species involved in the infection. There was no restriction regarding the language of the article and all publications dated from January 1, 1950 to August 1, 2019 were included. Therefore, all reviews, opinion articles, and letters not offering original data as well as studies reporting cases with incomplete information were excluded.

\section{Information sources and search strategy}

The relevant articles were searched in three databases, including Medline/PubMed, Scopus, and Web of Science. The search terms included "ehrlichiosis," "Ehrlichia", "bovine", "cattle", "Cowdria," and "Anaplasmataceae", using multiple combinations of the main Boolean operators (AND, OR). The search process ended by August 1, 2019. The obtained results were articles in English, Spanish, and Portuguese. Four different researchers independently evaluated the search results in order to reduce the risk of bias in the interpretations.

\section{Study selection}

Initial search strategy results were screened by the title and abstract. The full texts of relevant articles were examined for inclusion and exclusion criteria (Figure 1). When an article reported duplicate information, reports were combined in order to obtain complete data. Observational studies that reported Ehrlichia species detection using different diagnostic methods were included for quantitative synthesis (meta-analysis).

\section{Data collection process and data items}

Data extraction forms, including information on the type of publication, country, year, date of publication, Ehrlichia species detection, and diagnostic method, were filled independently by four researchers. The fifth investigator checked the article list and data extractions to guarantee no duplicate articles or duplicate information and also resolved discrepancies about the included studies.

\section{Assessment of methodological quality and risk of bias}

The critical appraisal tool of the Quality Appraisal of Case Series Studies Checklist of the Institute of Health Economics (IHE) was used in the present study to assess the quality of cross-sectional studies (AXIS, IHE, 2014; Downes et al., 2016). Publication bias was assessed using a funnel-plot. A random-effects model was used to calculate the pooled prevalence and $95 \% \mathrm{CI}$ has shown varying degrees of data heterogeneity and the inherent heterogeneity in any systematic review of studies from the published literature. Egger's test was also performed for publication bias.

\section{Statistical approach}

Unit discordance for variables was resolved by converting all units to a standard measurement for each variable. Percentages and means \pm standard deviation (SDs) were calculated to describe the distributions of categorical and continuous variables, respectively. The baseline data were analyzed using the Stata version 14.0, licensed for Universidad Tecnológica de Pereira in Colombia. The meta-analyses were performed using Stata, and the software OpenMeta[Analyst] (Wallace et al., 2012), JASP (Version 0.12.2)®, and Comprehensive Meta-Analysis ve.3.3® licensed for Universidad Tecnológica de Pereira. Pooled prevalences and their 95\% confidence intervals (95\% CIs) were used to summarize the weighted effect size for each study grouping variable using a binary random-effects model (which takes into consideration sample sizes of individual studies) except for median age, where a continuous random-effect model was applied (DerSimonian-Laird procedure, Viechtbauer, 2010; Kontopantelis and Reeves, 2012). Measures of heterogeneity, including Cochran's Q statistic, $\mathrm{I}^{2}$ index, and tau-squared test, were estimated and reported. Subgroup analyses and meta-analyses were also performed for some variables of interest.

\section{RESULTS}

\section{Study selection and characteristics}

A total of 1051 articles were retrieved using the defined search strategy. After screening the abstracts and titles, 120 articles were selected for full-text assessment. Of these, 49 were excluded due to the lack of information on laboratory diagnosis, and 71 were finally included for final qualitative synthesis and meta-analysis (Figure 1). Table S1 shows the main characteristics of the included studies. The present review included 71 studies that were published between January 1, 1950 and August 1, 2019, most of which were from China (23.1\%), Zambia (19.2\%), Namibia (6.4\%), Cameroon (5.1\%), Tanzania (5.1\%), and Benin (5.1\%), among others (Table S1), including a total of 6,232 animals assessed by molecular methods. All the studies were cross-sectional ones (Table S1). The meta-analyses 
included the analysis of 10 variables (Table 1). Publication bias was assessed with a funnel plot for standard error, with no evidence of bias (Figure 2), but the Egger test suggested possible publication bias $(z=4.440 ; p<0.001)$. Kendall's tau test was reported as $0.087(\mathrm{p}=0.207)$.

\section{Main findings}

The median number of individuals per study was 55, with positive rates ranging from 0.14 to $82.4 \%$ (Table 1 ). The pooled molecular prevalence for Ehrlichia was $2.3 \%$ (95\% CI: $1.7-2.9 \%, \tau^{2}=0.001, \mathrm{I}^{2}=81.944, \mathrm{Q}=387.685, \mathrm{p}<0.001$ ) with the highest value of $82.4 \%$ for China (2016, Table 1, Figure 3). Studies identified the highest pooled molecular prevalence of $6.6 \%$ for E. canis $\left(95 \%\right.$ CI: $\left.0.6-12.7 \%, \mathrm{I}^{2}=90.74, \mathrm{Q}=43.208, \mathrm{p}<0.001\right)$, followed by E. ruminantium (n = 4,695 [75.33\%] 52 studies) with 1.7\% (95\% CI: 1.1-2.3\%, $\left.\mathrm{I}^{2}=77.29, \mathrm{Q}=224.569 ; \mathrm{p}<0.001\right)$ and E. chaffeensis with $1.5 \%$ (95\% CI: 0.0-0.3\%, $\left.\mathrm{I}^{2}=60.96, \mathrm{Q}=12.806, \mathrm{p}=0.025\right)$. Regarding E. minasensis, only one study was included (3\%, Table 1, Figure 4). In China, with 18 included studies, the prevalence was $1.8 \%$ (95\% CI: 0.7-3.0\%, I $\mathrm{I}^{2}=87.54, \mathrm{Q}=$ 136.50, p<0.001, Figure 5). In this regard, Asia (18 studies) and Africa (48 studies) contributed the most with the prevalence of $1.8 \%$ (95\% CI: $1.1-2.4 \%$ ). The molecular prevalence rate was reported as $13.2 \%$ (95\% CI: $0.6-27.0 \%$ ) in 5 studies conducted in Americas (Table 1, Figure 6). According to the diagnostic techniques, the higher prevalence was reached with DNA sequencing by $13.2 \%$ (95\% CI: 0.0-27.0\%, Figure 7) from which 12 studies were conducted on $B o s$ taurus (0.6\%, 95\% CI: 0.1-1.4\%) and 4 on Bos indicus (11.9\%, 95\% CI: 2.4-21.3\%, Figure 8, Table 1).

Table 1. Meta-analysis outcomes (random-effects model)

\begin{tabular}{lcccccccc}
\hline Variable & $\begin{array}{c}\text { Number of } \\
\text { Studies }\end{array}$ & $\begin{array}{c}\text { Pool Prevalence } \\
(\%)\end{array}$ & $\mathbf{9 5 \%} \mathbf{C I}^{*}$ & $\mathbf{n}$ & $\mathbf{Q}^{\dagger}$ & $\mathbf{I}^{\mathbf{2}}$ & $\mathbf{t}^{\mathbf{2}}$ & $\mathbf{p ~ v a l u e ~}^{\mathbf{2}}$ \\
\hline All & 71 & 2.3 & $1.7-2.9$ & 6,232 & 387.685 & 81.944 & 0.001 & $<0.001$ \\
E. canis & 5 & 6.6 & $0.6-12.7$ & 299 & 43.208 & 90.74 & $\mathrm{n} / \mathrm{c}$ & $<0.001$ \\
E. ruminantium & 52 & 1.7 & $1.1-2.3$ & 4,695 & 224.569 & 77.29 & $\mathrm{n} / \mathrm{c}$ & $<0.001$ \\
E. chaffeensis & 6 & 1.5 & $0.0-0.3$ & 396 & 12.806 & 60.96 & $\mathrm{n} / \mathrm{c}$ & 0.025 \\
China & 18 & 1.8 & $0.7-3.0$ & 2,035 & 136.450 & 87.54 & $\mathrm{n} / \mathrm{c}$ & $<0.001$ \\
Zambia & 15 & 2.4 & $0.8-4.1$ & 897 & 60.167 & 76.73 & $\mathrm{n} / \mathrm{c}$ & $<0.001$ \\
Africa & 48 & 1.8 & $1.1-2.4$ & 3,812 & 153.997 & 69.48 & $\mathrm{n} / \mathrm{c}$ & $<0.001$ \\
Asia & 18 & 1.8 & $0.7-3.0$ & 2,035 & 136.450 & 87.54 & $\mathrm{n} / \mathrm{c}$ & $<0.001$ \\
Bos indicus & 5 & 11.9 & $2.4-21.3$ & 442 & 49.371 & 91.9 & $\mathrm{n} / \mathrm{c}$ & $<0.001$ \\
Bos taurus & 13 & 0.6 & $0.1-1.4$ & 2,348 & 80.467 & 85.09 & $\mathrm{n} / \mathrm{c}$ & $<0.001$ \\
\hline
\end{tabular}

*95\% CI = 95\% confidence interval, $\mathbf{Q}^{\dagger}:$ Cochran’s Q statistic for heterogeneity, $\ddagger \mathrm{I}^{2}:$ Index for the degree of heterogeneity, $\S$ : Tau-squared measure of heterogeneity, $\mathrm{n} / \mathrm{c}$ : Not calculated.

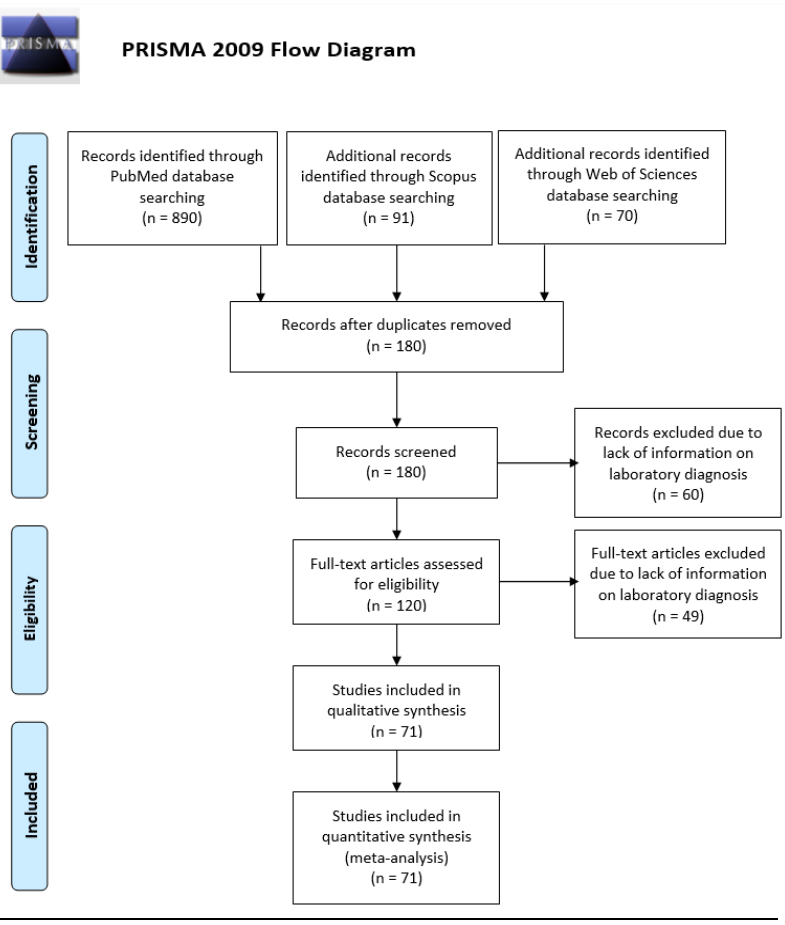

Figure 1. Study selection and characteristics

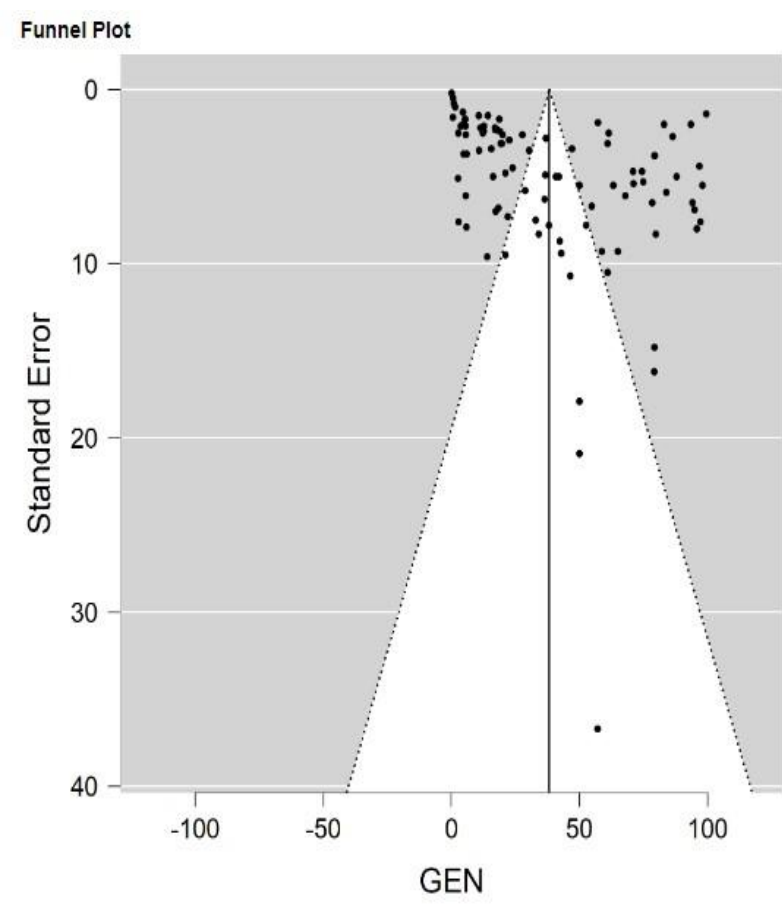

Figure 2. Funnel-plot for the standard error to assess for publication bias. 
EB-05 2016

EB-10 2018

EB-35 1998

EB-33 2015

EB-39 2019

EB-05-B 2016

EB-39-X 2019

EB-05-C 2016

EB-08 2018

EB-08-B 2018

EB-10-ZZ 2018

EB-39-T 2019

EB-49 2018

EB-49-B 2018

EB-39-C 2019

EB-05-D 2016

EB-33-B 2015

EB-06 2011

EB-47 2013

EB-49-C 2018

EB-39-D 2019

EB-06-X 2011

EB-49-D 2018

EB-35-O 1998

EB-10-O 2018

EB-10-B 2018

EB-09 2018

EB-09-B 2018

EB-09-C 2018

EB-08-C 2018

EB-05-E 2016

EB-13 2017

EB-05-F 2016

EB-02 2017

EB-05-G 2016

EB-13-UI 2017

EB-41 2016

EB-05-OPO 2016

EB-11-W 2019

EB-05-H 2016

EB-05-I 2016

EB-05-J 2016

EB-10-WW 2018

EB-10-BW 2018

EB-07 2016

EB-07-B 2016

EB-10-C 2018

EB-05-K 2016

EB-33-ER 2015

EB-02-B 2017

EB-02-C 2017

EB-10-BF 2018

EB-10-CF 2018

EB-33-F 2015

EB-05-GKKI 2016

EB-10-TOP 2018

EB-10-U 2018

EB-10-V 2018

EB-05-RYT 2016

EB-05-HFG 2016

EB-02-S 2017

EB-06-J 2011

EB-47-QW 2013

EB-10-X 2018

EB-10-Y 2018

EB-10-Z 2018

EB-06-TUI 2011

EB-06-CC 2011

EB-08-XX 2018

EB-33-RR 2015
EB-06-B 2011

$0.824(0.642,1.000) \quad 14 / 17$

$0.337(0.242,0.432) \quad 32 / 95$

$0.267(0.108,0.425) \quad 8 / 30$

$0.257(0.202,0.312) \quad 63 / 245$

$0.220(0.105,0.335) \quad 11 / 50$

$0.203(0.111,0.294) \quad 15 / 74$

$0.180(0.074,0.286) \quad 9 / 50$

$0.179(0.121,0.236) \quad 30 / 168$

$0.167(0.000,0.465) \quad 1 / 6$

$0.132(0.056,0.208) \quad 10 / 76$

$0.126(0.060,0.193) \quad 12 / 95$

$0.120(0.030,0.210) \quad 6 / 50$

$0.108(0.032,0.183) \quad 7 / 65$

$0.100(0.024,0.176) \quad 6 / 60$

$0.094(0.000,0.195) \quad 3 / 32$

$0.083(0.000,0.194) \quad 2 / 24$

$0.083(0.000,0.240) \quad 1 / 12$

$0.067(0.000,0.193) \quad 1 / 15$

$0.067(0.000,0.193) \quad 1 / 15$

$0.060(0.000,0.126) \quad 3 / 50$

$0.050(0.000,0.105) \quad 3 / 60$

$0.050(0.000,0.118) \quad 2 / 40$

$0.045(0.000,0.132) \quad 1 / 22$

$0.033(0.000,0.079) \quad 2 / 60$

$0.033(0.000,0.098)-1 / 30$

$0.020(0.000,0.059) \quad 1 / 50$

$0.020(0.000,0.047) \quad 2 / 102$

$0.018(0.000,0.053)$

$0.017(0.000,0.050)$

$0.016(0.000,0.047)$

$0.010(0.000,0.030)$

$0.009(0.000,0.027)$

$0.005(0.000,0.012)$

$0.005(0.000,0.012)$

$0.015(0.000,0.045)$

$0.004(0.000,0.011)$

$0.003(0.000,0.008)$

$0.001(0.000,0.004)$

$0.002(0.000,0.007)$

$0.003(0.000,0.012)$

$0.004(0.000,0.014)$

$0.004(0.000,0.017)$

$0.005(0.000,0.017)$

$0.005(0.000,0.018)$

$0.005(0.000,0.018)$

$0.005(0.000,0.019)$

$0.005(0.000,0.019)$

$0.005(0.000,0.020)$

$0.005(0.000,0.020)$

$0.141(0.067,0.215)$

$0.008(0.000,0.030)$

$0.008 \quad(0.000,0.031)$

$0.010(0.000,0.037)$

$0.010(0.000,0.037)$

$0.011(0.000,0.043)$

$0.012(0.000,0.044)$

$0.013(0.000,0.048)$

$0.013(0.000,0.048)$

$0.013(0.000,0.048)$

$0.015(0.000,0.055)$

$0.017(0.000,0.062)$

$0.024(0.000,0.089)$

$0.026(0.000,0.098)$

$0.031(0.000,0.117)$

$0.033(0.000,0.124)$

$0.033(0.000,0.124)$

$0.033(0.000,0.124)$

$0.036(0.000,0.133)$

$0.038(0.000,0.143)$

$0.500(0.000,1.000)$

$0.500(0.000,1.000)$

Overall (I^ $2=81.94 \%, P<0.001) \quad 0.023 \quad(0.017,0.029) \quad 272 / 6232$

$1 / 55$

$1 / 59$

$1 / 62$

$1 / 100$

$1 / 109$

$2 / 392$

$2 / 395$

$1 / 66$

$1 / 269$

$1 / 392$

$1 / 704$

$0 / 157$

$0 / 132$

$0 / 111$

$0 / 107$

$0 / 102$

$0 / 102$

$0 / 97$

$0 / 97$

$0 / 95$

$0 / 94$

$12 / 85$
$0 / 61$

$0 / 60$

$0 / 50$

$0 / 50$

$0 / 43$

$0 / 42$

$0 / 38$

$0 / 38$

$0 / 38$

$0 / 33$

$0 / 29$

$0 / 20$

$0 / 18$

$0 / 15$

$0 / 14$

$0 / 14$

$0 / 14$

$0 / 13$

$0 / 12$

$0 / 0$

$0 / 0$
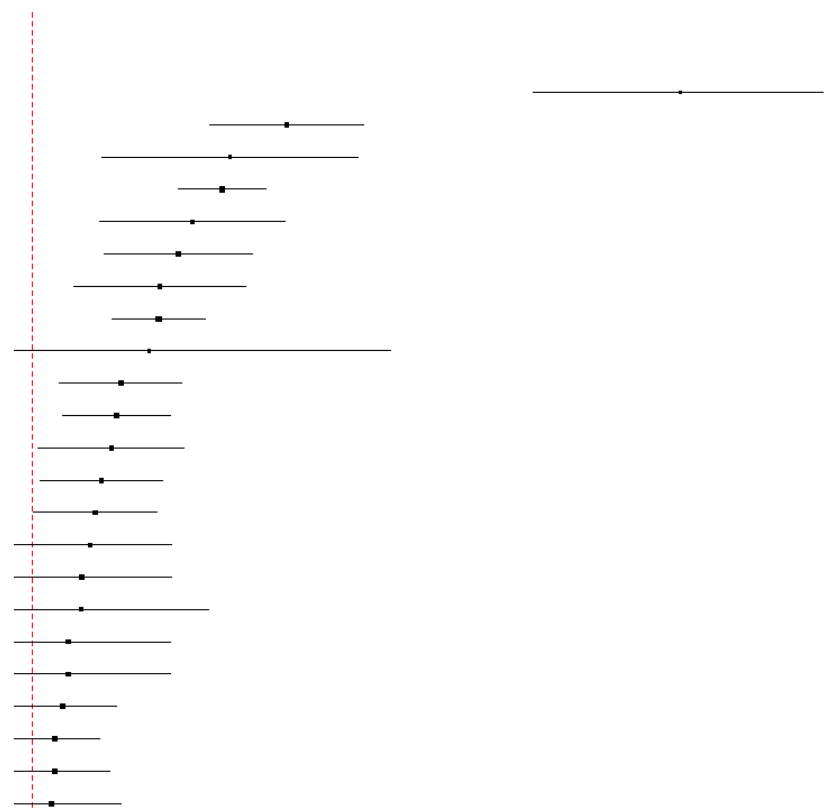

$-$

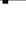

$-$

-

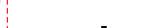

-

$-$

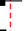

$-$

$-$

$-$

$-$

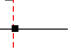

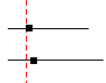

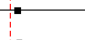

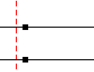

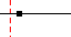
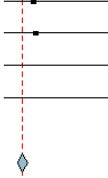

\begin{tabular}{lllll|l}
\hline 0 & 1 & 1 & 1 & 1 \\
0.2 & 0.4 & & 0.8 & 1
\end{tabular}

Figure 3. Pool prevalence forest plot of bovine ehrlichiosis

4

To cite this paper: Bonilla-Aldana DK, Quintero-Rada K, Montoya-Posada JP, Soler-Tovar D, Barato P, Arteaga-Livias K, Zambrano LI, Faccini-Martínez ÁA and 


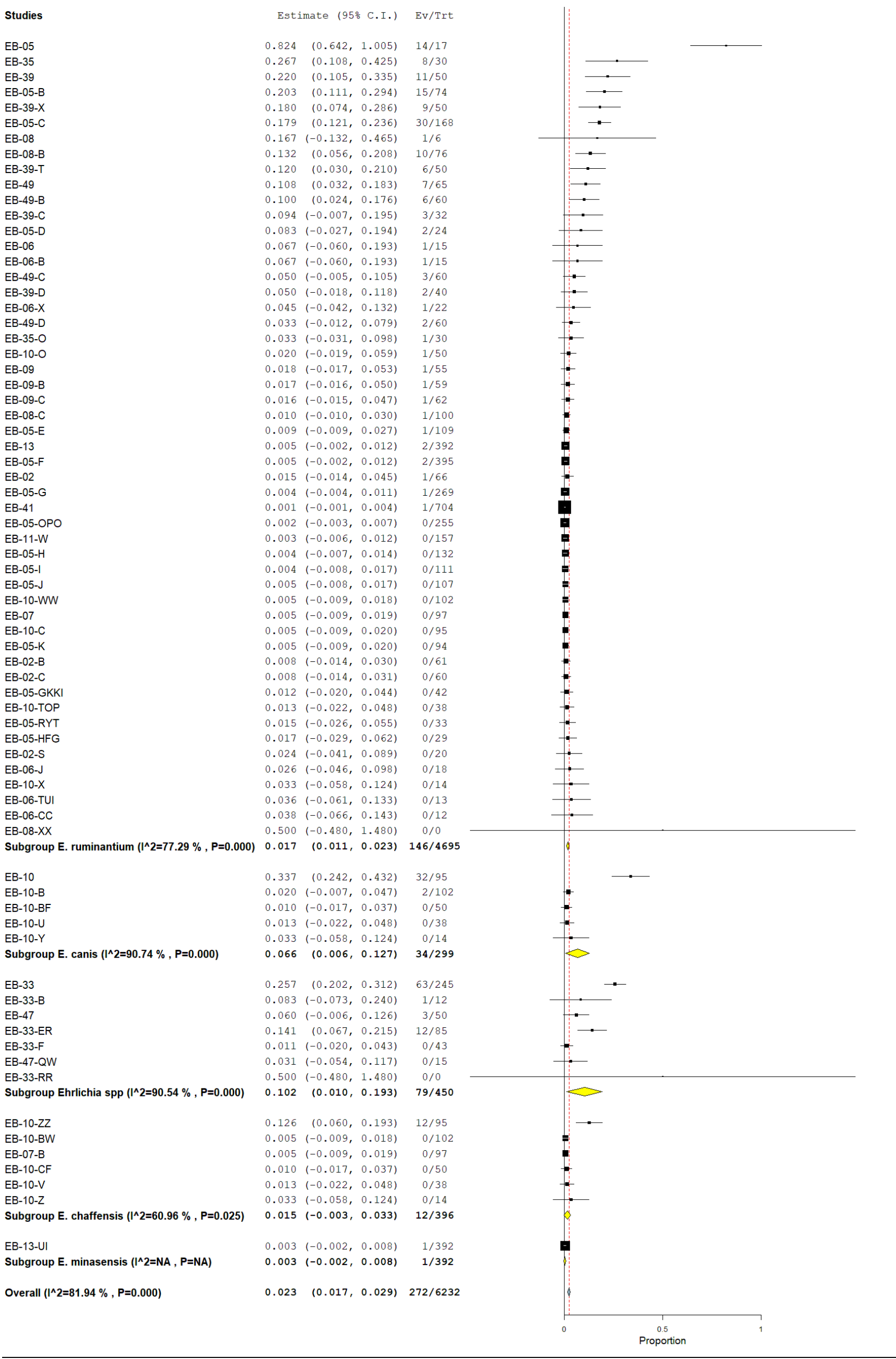

Figure 4. Pool prevalence forest plot of bovine ehrlichiosis based on Ehrlichia species 


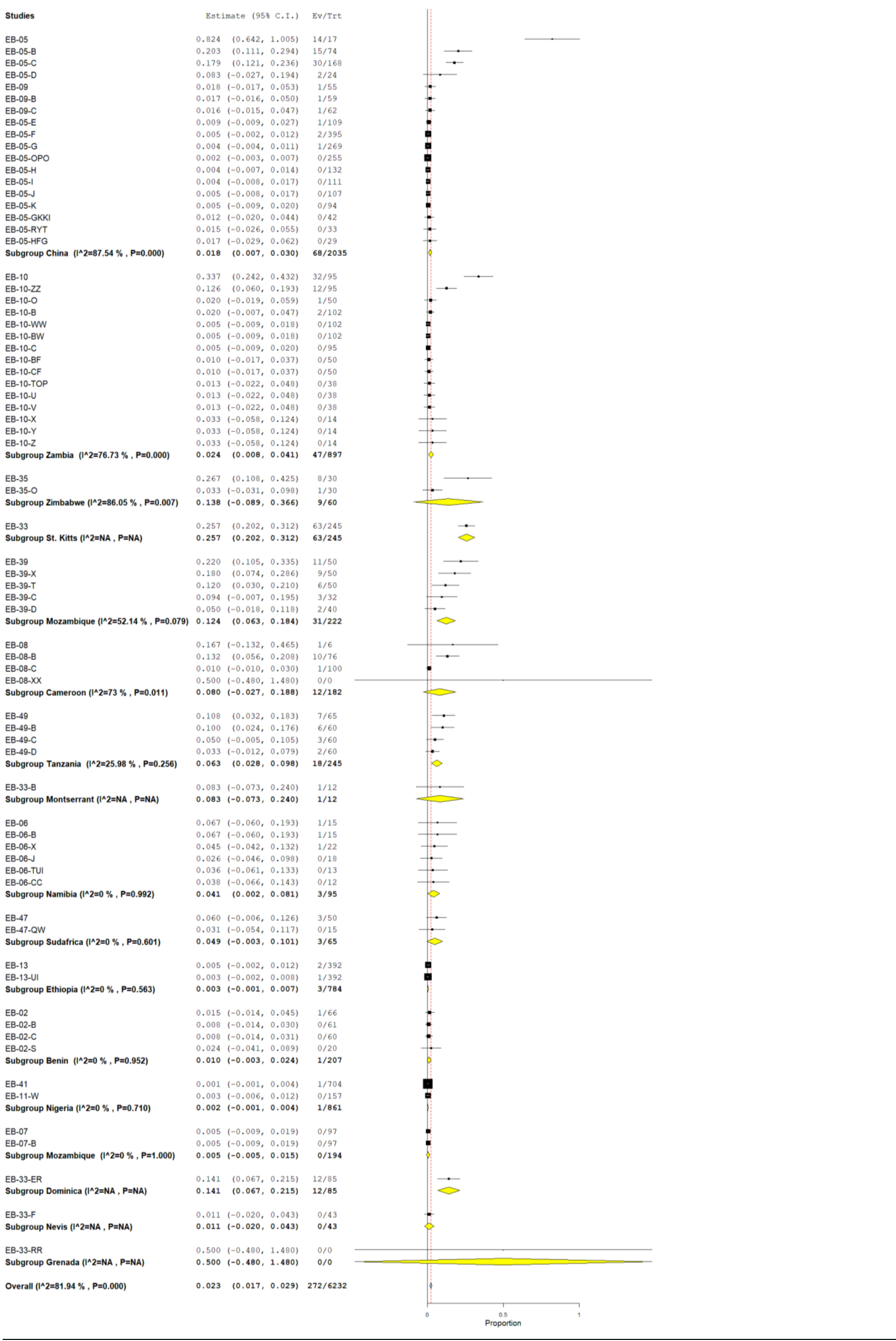

Figure 5. Pool prevalence forest plot of bovine ehrlichiosis based on countries 
EB-05

EB-05-B

EB-05-C

EB-05-D

EB-09

EB-09-B

EB-09-C

EB-05-E

EB-05-F

EB-05-G

EB-05-OPO

EB-05-H

EB-05-I

EB-05-J

EB-05-K

EB-05-GKK

EB-05-RYT

EB-05-HFG

Subgroup Asia $\left(I^{\wedge} 2=87.54 \%, P=0.000\right)$

EB-10

EB-35

EB-39

EB-39-X

EB-08

EB-08-B

EB-10-ZZ

EB-39-T

EB-49

EB-49-B

EB-39-C

EB-06

EB-06-B

EB-47

EB-49-C

EB-39-D

EB-06-X

EB-49-D

EB-35-O

EB-10-O

EB-10-B

EB-08-C

EB-13

EB-02

EB-13-UI

EB-41

EB-11-W

EB-10-WW

EB-10-BW

EB-07

EB-07-B

EB-10-C

EB-02-B

EB-02-C

EB-10-BF

EB-10-CF

EB-10-TOP

EB-10-U

EB-10-V

EB-02-S

EB-06-J

EB-47-QW

EB-10-X

EB-10-Y

EB-10-Z

EB-06-TUI

EB-06-CC

EB-08-XX

Subgroup Africa $\left(I^{\wedge} 2=69.48 \%, P=0.000\right)$

EB-33

EB-33-B

EB-33-ER

EB-33-F

EB-33-RR

Subgroup Americas $\left(\left.\right|^{\wedge} 2=93.55 \%, P=0.000\right)$

Overall $\left(\left.\right|^{\wedge} 2=81.94 \%, P=0.000\right)$
$0.824 \quad(0.642,1.005)$

$0.203(0.111,0.294) \quad 15 / 74$

$0.179 \quad(0.121,0.236) \quad 30 / 168$

$0.083(-0.027,0.194) \quad 2 / 24$

$0.018(-0.017,0.053) \quad 1 / 55$

$0.017(-0.016,0.050) \quad 1 / 59$

$0.016(-0.015,0.047) \quad 1 / 62$

$0.009(-0.009,0.027) \quad 1 / 109$

$0.005(-0.002,0.012) \quad 2 / 395$

$0.004(-0.004,0.011) \quad 1 / 269$

$0.002(-0.003,0.007) \quad 0 / 255$

$0.004(-0.007,0.014) \quad 0 / 132$

$0.004(-0.008,0.017) 0 / 111$

$0.005(-0.008,0.017) \quad 0 / 107$

$0.005(-0.009,0.020) \quad 0 / 94$

$0.012(-0.020,0.044) \quad 0 / 42$

$0.015(-0.026,0.055) \quad 0 / 33$

$0.017(-0.029,0.062) \quad 0 / 29$

$0.018 \quad(0.007,0.030) \quad 68 / 2035$

$0.337 \quad(0.242,0.432) \quad 32 / 95$

$0.267 \quad(0.108,0.425) \quad 8 / 30$

$0.220 \quad(0.105,0.335) \quad 11 / 50$

$0.180 \quad(0.074,0.286) \quad 9 / 50$

$0.167(-0.132,0.465) \quad 1 / 6$

$0.132 \quad(0.056,0.208) \quad 10 / 76$

$0.126 \quad(0.060,0.193) \quad 12 / 95$

$0.120 \quad(0.030,0.210) \quad 6 / 50$

$0.108 \quad(0.032,0.183) \quad 7 / 65$

$0.100 \quad(0.024,0.176) \quad 6 / 60$

$0.094(-0.007,0.195) \quad 3 / 32$

$0.067(-0.060,0.193) \quad 1 / 15$

$0.067(-0.060,0.193) \quad 1 / 15$

$0.060(-0.006,0.126) \quad 3 / 50$

$0.050(-0.005,0.105) \quad 3 / 60$

$0.050(-0.018,0.118) \quad 2 / 40$

$0.045(-0.042,0.132) \quad 1 / 22$

$0.033(-0.012,0.079) \quad 2 / 60$

$0.033(-0.031,0.098) \quad 1 / 30$

$0.020(-0.019,0.059) \quad 1 / 50$

$0.020(-0.007,0.047) \quad 2 / 102$

$0.010(-0.010,0.030) \quad 1 / 100$

$0.005(-0.002,0.012) \quad 2 / 392$

$0.015(-0.014,0.045) \quad 1 / 66$

$0.003(-0.002,0.008) \quad 1 / 392$

$0.001(-0.001,0.004) \quad 1 / 704$

$0.003(-0.006,0.012) \quad 0 / 157$

$0.005(-0.009,0.018) \quad 0 / 102$

$0.005(-0.009,0.018) \quad 0 / 102$

$0.005(-0.009,0.019) \quad 0 / 97$

$0.005(-0.009,0.019) \quad 0 / 97$

$0.005(-0.009,0.020) \quad 0 / 95$

$0.008(-0.014,0.030) \quad 0 / 61$

$0.008(-0.014,0.031) \quad 0 / 60$

$0.010(-0.017,0.037) \quad 0 / 50$

$0.010(-0.017,0.037) \quad 0 / 50$

$0.013(-0.022,0.048) \quad 0 / 38$

$0.013(-0.022,0.048) \quad 0 / 38$

$0.013(-0.022,0.048) \quad 0 / 38$

$0.024(-0.041,0.089) \quad 0 / 20$

$0.026(-0.046,0.098) \quad 0 / 18$

$0.031(-0.054,0.117) \quad 0 / 15$

$0.033(-0.058,0.124) \quad 0 / 14$

$0.033(-0.058,0.124) \quad 0 / 14$

$0.033(-0.058,0.124) \quad 0 / 14$

$0.036(-0.061,0.133) \quad 0 / 13$

$0.038(-0.066,0.143) \quad 0 / 12$

$0.500(-0.480,1.480) \quad 0 / 0$

$0.018(0.011,0.024) 128 / 3812$

$0.257 \quad(0.202,0.312) \quad 63 / 245$

$0.083(-0.073,0.240)-1 / 12$

$0.141 \quad(0.067,0.215) \quad 12 / 85$

$0.011(-0.020,0.043) \quad 0 / 43$

$0.500(-0.480,1.480) \quad 0 / 0$

$0.132(-0.006,0.270) \quad 76 / 385$

$0.023 \quad(0.017,0.029) 272 / 6232$

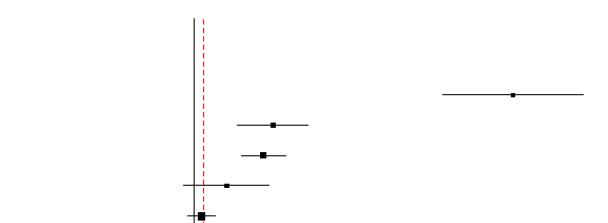


$0.050(-0.005,0.105)$

$0.050(-0.018,0.118) \quad 2 / 40$

$0.045(-0.042,0.132) \quad 1 / 22$

$0.033(-0.012,0.079) \quad 2 / 60$

$0.033(-0.031,0.098)-1 / 30$

$0.009(-0.009,0.027) \quad 1 / 109$

$0.005(-0.002,0.012) \quad 2 / 392$

$0.005(-0.002,0.012) \quad 2 / 395$

$0.004(-0.004,0.011) \quad 1 / 269$

$0.003(-0.002,0.008) \quad 1 / 392$

$0.001(-0.001,0.004) \quad 1 / 704$

$0.002(-0.003,0.007) \quad 0 / 255$

$0.004 \quad(-0.007,0.014) \quad 0 / 132$

$0.004(-0.008,0.017) \quad 0 / 111$

$0.005(-0.008,0.017) \quad 0 / 107$

$0.005(-0.009,0.020) \quad 0 / 94$

$0.012(-0.020,0.044) \quad 0 / 42$

$0.015(-0.026,0.055) \quad 0 / 33$

$0.017(-0.029,0.062)-0 / 29$

$0.026(-0.046,0.098) \quad 0 / 18$

$0.031(-0.054,0.117) \quad 0 / 15$

$0.036(-0.061,0.133) \quad 0 / 13$

$0.038(-0.066,0.143) \quad 0 / 12$

$0.020 \quad(0.012,0.028) \quad 133 / 4034$

EB-06-CC

Subgroup PCR (I^2=82.89\% , P=0.000)

$0.337 \quad(0.242,0.432) \quad 32 / 95$

$\begin{array}{llll}0.126 & (0.060,0.193) & 12 / 95\end{array}$

$0.020(-0.019,0.059) \quad 1 / 50$

$0.020(-0.007,0.047) \quad 2 / 102$

$0.005(-0.009,0.018) \quad 0 / 102$

$0.005(-0.009,0.018) \quad 0 / 102$

$0.005(-0.009,0.020) \quad 0 / 95$

$0.010(-0.017,0.037) \quad 0 / 50$

$0.010(-0.017,0.037)=0 / 50$

$0.013(-0.022,0.048) \quad 0 / 38$

$0.013(-0.022,0.048) \quad 0 / 38$

$0.013(-0.022,0.048) \quad 0 / 38$

$0.033(-0.058,0.124) \quad 0 / 14$

$0.033(-0.058,0.124) \quad 0 / 14$

$0.033(-0.058,0.124) \quad 0 / 14$

$0.024 \quad(0.008,0.041) \quad 47 / 897$

$0.257 \quad(0.202,0.312) \quad 63 / 245$

$0.083(-0.073,0.240) \quad 1 / 12$

$0.141 \quad(0.067,0.215) \quad 12 / 85$

$0.011(-0.020,0.043) \quad 0 / 43$

$0.500(-0.480,1.480) \quad 0 / 0$

$0.132(-0.006,0.270) \quad 76 / 385$

$0.167(-0.132,0.465)$

$0.132(0.056,0.208)$

$0.010(-0.010,0.030)$

$0.500(-0.480,1.480)$

EB-08-B

EB-08-XX

Subgroup PCR pCS20 seminested $(\mid \wedge 2=73 \%, P=0.011)$

$0.018(-0.017,0.053)$ $0.017(-0.016,0.050)$ $0.016(-0.015,0.047)$ $0.017(-0.002,0.036)$

$1 / 6$

$10 / 76$

$0 / 0$

$12 / 182$

EB-09

EB-09-B

$1 / 55$
$1 / 59$

$1 / 59$

Subgroup PCR nested $\left(I^{\wedge} 2=0 \%, P=0.996\right)$

$0.015(-0.014,0.045)$ $0.008(-0.014,0.030)$

$0.008(-0.014,0.031)$

$0.024(-0.041,0.089)$

$0.010(-0.003,0.024)$

$0.003(-0.006,0.012)$

$0.005(-0.009,0.019)$

$0.005(-0.009,0.019)$

$0.004(-0.003,0.011)$

$3 / 176$

EB-02-B

EB-02-

Subgroup nPCR (|^2=0 \% , P=0.952)

EB-11-W

EB-07

Subgroup $q P C R\left(\left.\right|^{\wedge} 2=0 \%, P=0.960\right)$

$0.023(0.017,0.029) 272 / 6232$

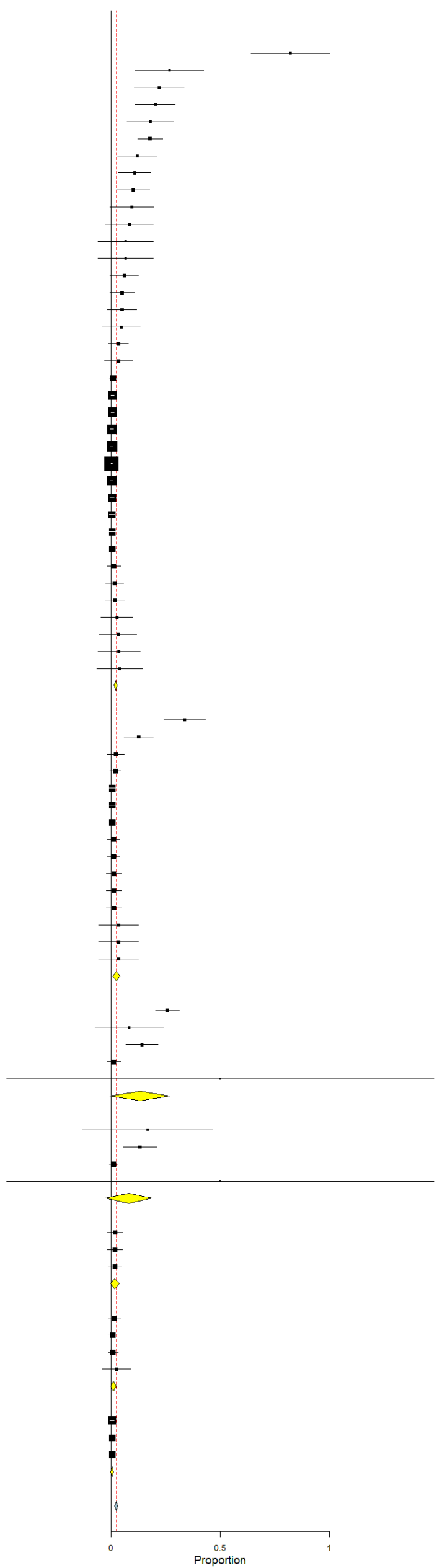

Figure 7. Pool prevalence forest plot of bovine ehrlichiosis based on the employed technique 


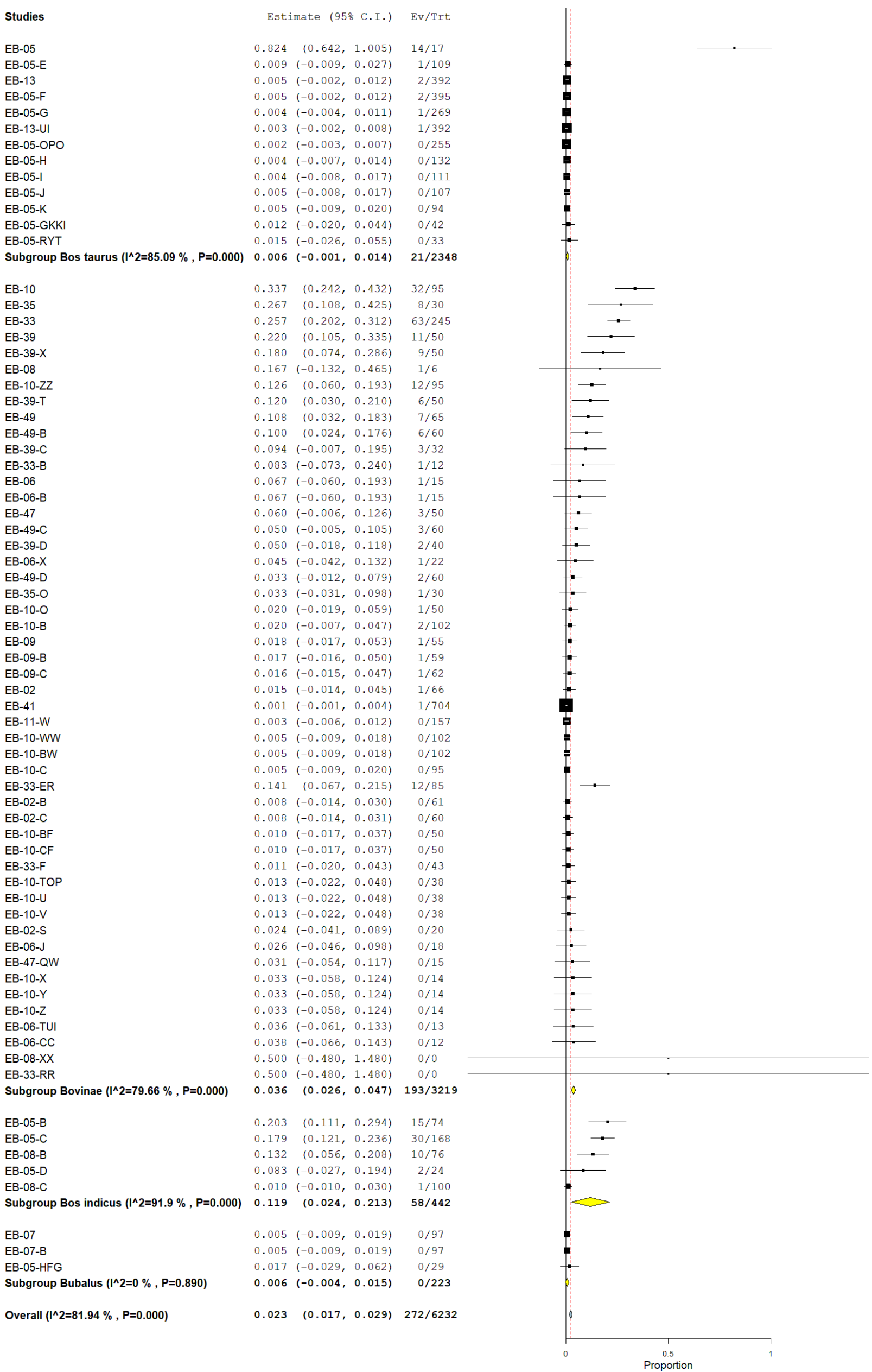

Figure 8. Pool prevalence forest plot of bovine ehrlichiosis based on animal species 
Heartwater (caused by E. ruminantium infection) is a notifiable disease listed by the World Organization for Animal Health (OIE) (Allsopp, 2015). Ehrlichia ruminantium, is a Gram-negative bacterium, belonging to the order Rickettsiales and the family Anaplasmataceae which is an obligately intracellular organism. Heartwater or cowdriosis is a tick-borne disease transmitted by species in the genus Amblyomma, and occurs in wild and domestic ruminants, primarily in Africa, and in some parts of the Caribbean (Allsopp, 2015). The disease was recognized in South Africa in the $19^{\text {th }}$ Century and determined to be tick-borne in 1900 while the organism was identified in 1925 and first cultured in vitro in 1985 (Allsopp, 2015).

Some authors suggest that the risk that endemic heartwater could pose in the Americas is relevant possible given the climate and the presence of some tick species, including A. maculatum as it is a good experimental vector for E. ruminantium (Vachiery et al., 2013). The existence of heartwater on three islands of the Central Lesser Antilles and the presence of an efficient vector originating from Africa, Amblyomma variegatum, on most of the islands of this region can present a serious threat for livestock on the American mainland (Barre et al., 1987).

In addition to E. ruminantium, E. minasensis (Aguiar et al., 2019), E. chaffeensis (Zhang et al., 2015), and E. canis (Seo et al., 2020) have been reported in cattle (Gajadhar et al., 2010; Aguiar et al., 2014; Moura de Aguiar et al., 2019). Nevertheless, considering the strong phylogenetic relationships of E. canis and E. chaffeensis with E. minasensis, plus the wide distribution of the latter species in the Americas, Europe, Asia, and Africa, it is possible that the molecular detection of E. canis/E. chaffeensis in bovines are false positives or an inadequate molecular identification (cross detection due to unspecificity of the primers), being really E. minasensis, as common primers used in the PCR are unable to discriminate such species (Thomson et al., 2018; Cabezas-Cruz et al., 2019). Considering the above-mentioned points, the only species of Ehrlichia that naturally infect cattle are E. ruminantium and E. minasensis (Gajadhar et al., 2010; Vachiery et al., 2013; Aguiar et al., 2014; Moura de Aguiar et al., 2019), which would affect the obtained results on E. ruminantium. The molecular prevalence for E. ruminantium would be higher than for E. canis. Although the most similar species to E. minasensis is E. canis, E. chaffeensis is also quite close phylogenetically (Cabezas-Cruz et al., 2016), which may also affect the results. Recently, some reports, not included in the current analyses as they did not correspond to the prevalence studies, indicated the circulation of E. minasensis in Canada and Brazil in cattle (Gajadhar et al., 2010; Aguiar et al., 2014).

As indicated in this meta-analysis, the prevalence of Ehrlichia is low in bovine (2.3\%), higher for E. canis, which naturally infect dogs and other mammals without any significant difference from other species (Table 1). As expected, the higher prevalence was in an African country, Zambia (2.4\%) although there was no difference between Africa and Asia $(1.8 \%)$ regarding the worldwide prevalence (Table 1$)$.

Unexpectedly, the prevalence was significantly higher in Bos indicus (11.9\%, 95\% CI: 2.4-21.3\%) than Bos taurus $(0.6 \%, 95 \%$ CI: $0.1-1.4 \%$, Table 1) although B. taurus is more susceptible to ticks than B. indicus. It is known that tick resistance in cattle varies from more tick-susceptible Bos taurus taurus (B. t. taurus) to more tick-resistant B. $t$. indicus breeds, between bovine crosses as well as within a single cattle breed. Most of the studies have indicated that resistance is acquired through exposure to ticks (Roberts, 1968; George et al., 1985; Wambura et al., 1998; Robbertse et al., 2017).

Considering the large populations of cattle in different regions of the world, especially in those countries where bovine ehrlichiosis is not usually considered, they may be potentially affected by E. ruminantium. Accordingly, there is a need to conducte more studies on this specific pathogen. In this setting is also worthy to say that E. minasensis should be considered as a probable emerging etiology in bovine ehrlichiosis based on the obtained results of natural infection in cattle residing in Canada, Brazil, and Ethiopia (Gajadhar et al., 2010; Aguiar et al., 2014), in addition to the detection in ticks collected from cattle in countries, such as Pakistan (Rehman et al., 2019), China (Li et al., 2019), Malaysia (Koh et al., 2018), South Africa (Iweriebor et al., 2017), and Corsica (France, Cicculli et al., 2019).

\section{CONCLUSION}

As the findings indicated, heartwater, E. ruminantium infection, is a notifiable disease of domestic and wild ruminants, listed by the World Organization for Animal Health (OIE) although still needs to be meticulously investigated in different continents and countries. Its specific diagnosis is complex, as the serological and molecular diagnostic tests are insufficient to achieve a correct species identification which highlights the importance of genomic surveillance and phylogenetic analyses. There is a possible risk of endemic heartwater in the Americas due to the climate and the apparent increase in multiple infectious and vector-borne diseases, including ehrlichiosis. Furthermore, E. minasensis, E. chaffeensis, and E. canis have been reported in cattle although the two last species could be a molecular misidentification given their phylogenetic relationships with E. minasensis. 
This study was previously presented in part at the XVII Colombian Congress of Parasitology and Tropical Medicine, Cali, Colombia, December 4-6, 2019 (Poster D96) and at the VI Symposium of Research of the Fundacion Universitaria Autonoma de las Americas, Pereira, Colombia, October 30, 2019 (Oral Presentation, Preliminary Main Results).

\section{Authors' contributions}

DKBA conceived the idea of the study. KQR, JPMP, collected data. AJRM and DKBA analyzed data. AJRM wrote the first draft. DKBA, KQR, JPMP, DST, PB, KAL, LIZ, and AAFM wrote and revised the subsequent drafts. All authors approved the final submitted version and the data analysis.

\section{Funding}

From the Dirección de Investigación Científica, Humanística y Tecnológica (2-05-01-01), National Autonomous University of Honduras, Tegucigalpa, MDC, Honduras, Central America.

\section{Competing interests}

All authors declare no competing interests to be reported.

\section{REFERENCES}

Aguiar DM, Araujo JP, Nakazato L, Bard E, and Cabezas-Cruz A (2019). Complete genome sequence of an ehrlichia minasensis strain isolated from cattle. Microbiology Resource Announcements, 8(15): e00161-19. DOI: https://www.doi.org/10.1128/MRA.00161-19

Aguiar DM, Ziliani TF, Zhang X, Melo AL, Braga IA, Witter R, Freitas LC, Rondelli AL, Luis MA, Sorte EC et al. (2014). A novel ehrlichia genotype strain distinguished by the trp36 gene naturally infects cattle in brazil and causes clinical manifestations associated with ehrlichiosis. Ticks and Tick-borne Diseases, 5(5): 537-544. DOI: https://www.doi.org/10.1016/j.ttbdis.2014.03.010

Allsopp BA (2015). Heartwater--ehrlichia ruminantium infection. Revue Scientifique et Technique, 34(2): 557-568. DOI: https://www.doi.org/10.20506/rst.34.2.2379

Anifowose OI, Takeet MI, Talabi AO, and Otesile EB (2020). Molecular detection of ehrlichia ruminantium in engorged ablyomma variegatum and cattle in ogun state, nigeria. Journal of Parasitic Diseases, 44(2): 403-410. DOI: https://www.doi.org/10.1007/s12639-020-01218-4

Barre N, Uilenberg G, Morel PC, and Camus E (1987). Danger of introducing heartwater onto the american mainland: Potential role of indigenous and exotic amblyomma ticks. Onderstepoort Journal of Veterinary Research, 54(3): 405-417. Available at: https://pubmed.ncbi.nlm.nih.gov/3329328/

Cabezas-Cruz A, Zweygarth E, and Aguiar DM (2019). Ehrlichia minasensis, an old demon with a new name. Ticks and Tick-borne Diseases, 10(4): 828-829. DOI: https://www.doi.org/10.1016/j.ttbdis.2019.03.018

Cabezas-Cruz A, Zweygarth E, Vancova M, Broniszewska M, Grubhoffer L, Passos LMF, Ribeiro MFB, Alberdi P, and de la Fuente J (2016). Ehrlichia minasensis sp. Nov., isolated from the tick rhipicephalus microplus. International Journal of Systematic and Evolutionary Microbiology, 66(3): 1426-1430. DOI: https://www.doi.org/10.1099/ijsem.0.000895

Cicculli V, Masse S, Capai L, de Lamballerie X, Charrel R, and Falchi A (2019). First detection of ehrlichia minasensis in hyalomma marginatum ticks collected from cattle in corsica, france. Veterinary Medicine and Science, 5(2): 243-248. DOI: https://www.doi.org/10.1002/vms3.140

Downes MJ, Brennan ML, Williams HC, and Dean RS (2016). Development of a critical appraisal tool to assess the quality of cross-sectional studies (axis). BMJ Open, 6(12): e011458. DOI: https://www.doi.org/10.1136/bmjopen-2016-011458

Fargnoli L, Fernandez C, and Monje LD (2020). Novel ehrlichia strain infecting cattle tick amblyomma neumanni, argentina, 2018. Emerging Infectious Diseases Journal, 26(5): 1027-1030. DOI: https://www.doi.org/10.3201/eid2605.190940

Gajadhar AA, Lobanov V, Scandrett WB, Campbell J, and Al-Adhami B (2010). A novel ehrlichia genotype detected in naturally infected cattle in North America. Veterinary Parasitology, 173(3-4): 324-329. DOI: https://www.doi.org/10.1016/j.vetpar.2010.06.034

George JE, Osburn RL and Wikel SK (1985). Acquisition and expression of resistance by bos indicus and bos indicus $\mathrm{x}$ bos taurus calves to amblyomma americanum infestation. Journal of Parasitology, 71(2): 174-182. Available at https://pubmed.ncbi.nlm.nih.gov/3998956/

Hector E, Elelu N, Ferrolho J, Couto J, Sanches G, Antunes S, Domingos A, and Eisler M (2019). Pcr detection of ehrlichia ruminantium and babesia bigemina in cattle from kwara state, nigeria: Unexpected absence of infection. Parasitology Research, 118(3): 1025-1029. DOI: https://www.doi.org/10.1007/s00436-019-06204-1

Institute of Health Economics (IHE) (2014). Quality appraisal of case series studies checklist. Available at http://www.ihe.ca/researchprograms/rmd/cssqac/cssqac-about

Iweriebor BC, Mmbaga EJ, Adegborioye A, Igwaran A, Obi LC, and Okoh AI (2017). Genetic profiling for Anaplasma and Ehrlichia species in ticks collected in the eastern cape province of south africa. BMC Microbiology, 17(1): Article number: 45. DOI: https://www.doi.org/10.1186/s12866$\underline{017-0955-0}$

Koh FX, Kho KL, Kisomi MG, Wong LP, Bulgiba A, Tan PE, Lim YAL, Nizam QNH, Panchadcharam C, and Tay ST (2018). Ehrlichia and Anaplasma infections: Serological evidence and tick surveillance in peninsular malaysia. Journal of Medical Entomology, 55(2): 269-276. DOI: https://www.doi.org/10.1093/jme/tjx204

Kontopantelis E, and Reeves D (2012). Performance of statistical methods for meta-analysis when true study effects are non-normally distributed: A comparison between dersimonian-laird and restricted maximum likelihood. Statistical Methods in Medical Research, 21(6): 657-659. DOI: https://www.doi.org/10.1177/0962280211413451

Li J, Liu X, Mu J, Yu X, Fei Y, Chang J, Bi Y, Zhou Y, Ding Z, and Yin R (2019). Emergence of a novel Ehrlichia minasensis strain, harboring the major immunogenic glycoprotein trp36 with unique tandem repeat and c-terminal region sequences, in Haemaphysalis hystricis ticks removed from free-ranging sheep in Hainan province, China. Microorganisms 7(9): Article number: 369. DOI: https://www.doi.org/10.3390/microorganisms7090369 
Moher D, Liberati A, Tetzlaff J, Altman DG, and Group P (2009). Preferred reporting items for systematic reviews and meta-analyses: The prisma statement. PLOS Medicine, 6(7): e1000097. DOI: https://www.doi.org/10.1371/journal.pmed.1000097

Moura de Aguiar D, Pessoa Araujo Junior J, Nakazato L, Bard E, Aguilar-Bultet L, Vorimore F, Leonidovich Popov V, Moleta Colodel E, and Cabezas-Cruz A (2019). Isolation and characterization of a novel pathogenic strain of Ehrlichia minasensis. Microorganisms, 7(11): Article number: 528. DOI: https://www.doi.org/10.3390/microorganisms7110528

Rehman A, Conraths FJ, Sauter-Louis C, Krucken J, and Nijhof AM (2019). Epidemiology of tick-borne pathogens in the semi-arid and the arid agroecological zones of punjab province, Pakistan. Transboundary and Emerging Diseases, 66(1): 526-536. DOI: https://www.doi.org/10.1111/tbed.13059

Robbertse L, Richards SA, and Maritz-Olivier C (2017). Bovine immune factors underlying tick resistance: Integration and future directions. Frontiers in Cellular and Infection Microbiology, 7: Article number: 522. DOI: https://www.doi.org/10.3389/fcimb.2017.00522

Roberts JA (1968). Resistance of cattle to the tick boophilus microplus (canestrini). I. Development of ticks on bos taurus. Journal of Parasitology, 54(4): 663-666. Available at: https://www.jstor.org/stable/3277017?seq=1

Seo MG, Kwon OD, and Kwak D (2020). Genotypic analysis of piroplasms and associated pathogens from ticks infesting cattle in korea. Microorganisms, 8(5): Article number:728. DOI: https://www.doi.org/10.3390/microorganisms8050728

Stewart CG (1992). Bovine ehrlichiosis. Tick vector biology: Medical and veterinary aspects. Berlin, Heidelberg: Springer Berlin Heidelberg, pp. 101107. Available at: https://www.springer.com/gp/book/9783642766459

Thomson K, Yaaran T, Belshaw A, Curson L, Tisi L, Maurice S, and Kiddle G (2018). A new taqman method for the reliable diagnosis of ehrlichia spp. In canine whole blood. Parasites \& Vectors, 11(1): Article number: 350. DOI: https://www.doi.org/10.1186/s13071-018-2914-5

Vachiery N, Marcelino I, Martinez D, and Lefrancois T (2013). Opportunities in diagnostic and vaccine approaches to mitigate potential heartwater spreading and impact on the american mainland. Developmental Biology (Basel), 135: 191-200. DOI: https://www.doi.org/10.1159/000190050

Viechtbauer $\mathrm{W}$ (2010). Conducting meta-analyses in $\mathrm{r}$ with the metafor package. Journal of statistical software, 36(3): 1-48. DOI: https://www.doi.org/10.18637/jss.v036.i03

Wallace BC, Dahabreh IJ, Trikalinos TA, Lau J, Trow P, and Schmid CH (2012). Closing the gap between methodologists and end-users: R as a computational back-end. Journal of statistical software, 49(5): 1-15. DOI: https://www.doi.org/10.18637/jss.v049.i05

Wambura PN, Gwakisa PS, Silayo RS, and Rugaimukamu EA (1998). Breed-associated resistance to tick infestation in Bos indicus and their crosses with Bos taurus. Veterinary Parasitology, 77(1): 63-70. DOI: https://www.doi.org/10.1016/s0304-4017(97)00229-x

Zhang J, Kelly P, Guo W, Xu C, Wei L, Jongejan F, Loftis A, and Wang C (2015). Development of a generic Ehrlichia fret-qpcr and investigation of ehrlichioses in domestic ruminants on five caribbean islands. Parasites \& Vectors, 8: Article number: 506. DOI: https://www.doi.org/10.1186/s13071-015-1118-5 


\section{Supplementary Materials}

Table S1. Characteristics of the included studies on bovine ehrlichiosis

\begin{tabular}{|c|c|c|c|c|c|c|c|c|c|c|c|}
\hline Number/Code & Year-Publication & Years-Study & Ehrlichia & State & Country & Region & Lab Technique & Species & $\mathbf{N}$ & $\mathbf{n}(+)$ & $\%$ \\
\hline EB-05 & 2016 & $2007-2013$ & E. ruminantium & Wuhu, Anhui & China & Asia & PCR & Bos taurus & 17 & 14 & 82.4 \\
\hline EB-10 & 2018 & 2010 & E. canis & Kowa & Zambia & Africa & RLB & Bovinae & 95 & 32 & 33.68 \\
\hline EB-35 & 1998 & 1998 & E. ruminantium & & Zimbabwe & Africa & PCR & Bovinae & 30 & 8 & 26.7 \\
\hline EB-33 & 2015 & 2014 & Ehrlichia spp. & St. Kitts & St. Kitts & Americas & DNA seq & Bovinae & 245 & 63 & 25.7 \\
\hline EB-39 & 2019 & 2019 & E. ruminantium & Boane & Mozambique & Africa & PCR & Bovinae & 50 & 11 & 22 \\
\hline EB-05-B & 2016 & $2007-2013$ & E. ruminantium & Haikou, Hainan & China & Asia & PCR & Bos indicus & 74 & 15 & 20.3 \\
\hline EB-39-X & 2019 & 2019 & E. ruminantium & Magude & Mozambique & Africa & PCR & Bovinae & 50 & 9 & 18 \\
\hline EB-05-C & 2016 & $2007-2013$ & E. ruminantium & Kunming, Yunnan & China & Asia & PCR & Bos indicus & 168 & 30 & 17.9 \\
\hline EB-08 & 2018 & 2010 & E. ruminantium & SDR & Cameroon & Africa & PCR pCS20 seminested & Bovinae & 6 & 1 & 16.7 \\
\hline EB-08-B & 2018 & 2010 & E. ruminantium & SDR & Cameroon & Africa & PCR pCS20 seminested & Bos indicus & 76 & 10 & 13.9 \\
\hline EB-10-ZZ & 2018 & 2010 & E. chaffeensis & Kowa & Zambia & Africa & RLB & Bovinae & 95 & 12 & 12.63 \\
\hline EB-39-T & 2019 & 2019 & E. ruminantium & Matutuine & Mozambique & Africa & PCR & Bovinae & 50 & 6 & 12 \\
\hline EB-49 & 2018 & 2018 & E. ruminantium & Mkoani & Tanzania & Africa & PCR & Bovinae & 65 & 7 & 10.77 \\
\hline EB-49-B & 2018 & 2018 & E. ruminantium & Wete & Tanzania & Africa & PCR & Bovinae & 60 & 6 & 10 \\
\hline EB-39-C & 2019 & 2019 & E. ruminantium & Namaacha & Mozambique & Africa & PCR & Bovinae & 32 & 3 & 9.38 \\
\hline EB-05-D & 2016 & $2007-2013$ & E. ruminantium & Putian, Fujian & China & Asia & PCR & Bos indicus & 24 & 2 & 8.3 \\
\hline EB-33-B & 2015 & 2014 & Ehrlichia spp. & Montserrant & Montserrant & Americas & DNA seq & Bovinae & 12 & 1 & 8.3 \\
\hline EB-06 & 2011 & 2009 & E. ruminantium & Bwabwata-Mahango & Namibia & Africa & PCR & Bovinae & 15 & 1 & 6.67 \\
\hline EB-06-B & 2011 & 2009 & E. ruminantium & Bwabwata-Buffalo & Namibia & Africa & PCR & Bovinae & 15 & 1 & 6.67 \\
\hline EB-47 & 2013 & 2013 & Ehrlichia spp. & & Sudafrica & Africa & PCR & Bovinae & 50 & 3 & 6 \\
\hline EB-49-C & 2018 & 2018 & E. ruminantium & Chake & Tanzania & Africa & PCR & Bovinae & 60 & 3 & 5 \\
\hline EB-39-D & 2019 & 2019 & E. ruminantium & Moamba & Mozambique & Africa & PCR & Bovinae & 40 & 2 & 5 \\
\hline EB-06-X & 2011 & 2009 & E. ruminantium & Mamili & Namibia & Africa & PCR & Bovinae & 22 & 1 & 4.55 \\
\hline EB-49-D & 2018 & 2018 & E. ruminantium & Micheweni & Tanzania & Africa & PCR & Bovinae & 60 & 2 & 3.33 \\
\hline EB-35-O & 1998 & 1998 & E. ruminantium & & Zimbabwe & Africa & PCR & Bovinae & 30 & 1 & 3.3 \\
\hline EB-10-O & 2018 & 2010 & E. ruminantium & Kapamba & Zambia & Africa & RLB & Bovinae & 50 & 1 & 2 \\
\hline EB-10-B & 2018 & 2010 & E. canis & Chifulo & Zambia & Africa & RLB & Bovinae & 102 & 2 & 1.96 \\
\hline
\end{tabular}




\begin{tabular}{|c|c|c|c|c|c|c|c|c|c|c|c|}
\hline Number/Code & Year-Publication & Years-Study & Ehrlichia & State & Country & Region & Lab Technique & Species & $\mathbf{N}$ & $\mathbf{n}(+)$ & $\%$ \\
\hline EB-09 & 2018 & 2017 & E. ruminantium & kashgar & China & Asia & PCR nested & Bovinae & 55 & 1 & 1.8 \\
\hline EB-09-B & 2018 & 2017 & E. ruminantium & Yecheng & China & Asia & PCR nested & Bovinae & 59 & 1 & 1.7 \\
\hline EB-09-C & 2018 & 2017 & E. ruminantium & Hotan & China & Asia & PCR nested & Bovinae & 62 & 1 & 1.6 \\
\hline EB-08-C & 2018 & 2010 & E. ruminantium & UFR & Cameroon & Africa & PCR pCS20 seminested & Bos indicus & 100 & 1 & 1 \\
\hline EB-05-E & 2016 & $2007-2013$ & E. ruminantium & Bengbu, Anhui & China & Asia & PCR & Bos taurus & 109 & 1 & 0.9 \\
\hline EB-13 & 2017 & 2013 & E. ruminantium & Illubabor & Ethiopia & Africa & PCR & Bos taurus & 392 & 2 & 0.51 \\
\hline EB-05-F & 2016 & $2007-2013$ & E. ruminantium & Yancheng, Jiangsu & China & Asia & PCR & Bos taurus & 395 & 2 & 0.5 \\
\hline EB-02 & 2017 & 2015 & E. ruminantium & Gogounou & Benin & Africa & nPCR & Bovinae & 66 & 1 & 0.5 \\
\hline EB-05-G & 2016 & $2007-2013$ & E. ruminantium & Yangzjou, Jiangsu & China & Asia & PCR & Bos taurus & 269 & 1 & 0.4 \\
\hline EB-13-UI & 2017 & 2013 & E. minasensis & Illubabor & Ethiopia & Africa & PCR & Bos taurus & 392 & 1 & 0.26 \\
\hline EB-41 & 2016 & 2008 & E. ruminantium & Plateau & Nigeria & Africa & PCR & Bovinae & 704 & 1 & 0.14 \\
\hline EB-05-OPO & 2016 & $2007-2013$ & E. ruminantium & Shanghai, Shanghai & China & Asia & PCR & Bos taurus & 255 & 0 & 0 \\
\hline EB-11-W & 2019 & 2019 & E. ruminantium & Kwara & Nigeria & Africa & qPCR & Bovinae & 157 & 0 & 0 \\
\hline EB-05-H & 2016 & $2007-2013$ & E. ruminantium & Chifeng, Inner Mongolia & China & Asia & PCR & Bos taurus & 132 & 0 & 0 \\
\hline EB-05-I & 2016 & $2007-2013$ & E. ruminantium & Qiqihar, Heilongjjang & China & Asia & PCR & Bos taurus & 111 & 0 & 0 \\
\hline EB-05-J & 2016 & $2007-2013$ & E. ruminantium & Sanyuan, Beijing & China & Asia & PCR & Bos taurus & 107 & 0 & 0 \\
\hline EB-10-WW & 2018 & 2010 & E. ruminantium & Chifulo & Zambia & Africa & RLB & Bovinae & 102 & 0 & 0 \\
\hline EB-10-BW & 2018 & 2010 & E. chaffeensis & Chifulo & Zambia & Africa & RLB & Bovinae & 102 & 0 & 0 \\
\hline EB-07 & 2016 & 2011 & E. ruminantium & Reserve de Marromeu & Mozambique & Africa & qPCR & Bubalus & 97 & 0 & 0 \\
\hline EB-07-B & 2016 & 2011 & E. chaffeensis & Reserve de Marromeu & Mozambique & Africa & qPCR & Bubalus & 97 & 0 & 0 \\
\hline EB-10-C & 2018 & 2010 & E. ruminantium & Kowa & Zambia & Africa & RLB & Bovinae & 95 & 0 & 0 \\
\hline EB-05-K & 2016 & $2007-2013$ & E. ruminantium & Tianjin, Tianjin & China & Asia & PCR & Bos taurus & 94 & 0 & 0 \\
\hline EB-33-ER & 2015 & 2014 & Ehrlichia spp. & Dominica & Dominica & Americas & DNA seq & Bovinae & 85 & 12 & 14.1 \\
\hline EB-02-B & 2017 & 2015 & E. ruminantium & Tchaourou & Benin & Africa & $\mathrm{nPCR}$ & Bovinae & 61 & 0 & 0 \\
\hline EB-02-C & 2017 & 2015 & E. ruminantium & Nikki & Benin & Africa & nPCR & Bovinae & 60 & 0 & 0 \\
\hline EB-10-BF & 2018 & 2010 & E. canis & Kapamba & Zambia & Africa & RLB & Bovinae & 50 & 0 & 0 \\
\hline EB-10-CF & 2018 & 2010 & E. chaffeensis & Kapamba & Zambia & Africa & RLB & Bovinae & 50 & 0 & 0 \\
\hline EB-33-F & 2015 & 2014 & Ehrlichia spp. & Nevis & Nevis & Americas & DNA seq & Bovinae & 43 & 0 & 0 \\
\hline EB-05-GKKI & 2016 & $2007-2013$ & E. ruminantium & Jining, Shandong & China & Asia & PCR & Bos taurus & 42 & 0 & 0 \\
\hline EB-10-TOP & 2018 & 2010 & E. ruminantium & Chisanga & Zambia & Africa & RLB & Bovinae & 38 & 0 & 0 \\
\hline EB-10-U & 2018 & 2010 & E. canis & Chisanga & Zambia & Africa & RLB & Bovinae & 38 & 0 & 0 \\
\hline
\end{tabular}




\begin{tabular}{|c|c|c|c|c|c|c|c|c|c|c|c|}
\hline Number/Code & Year-Publication & Years-Study & Ehrlichia & State & Country & Region & Lab Technique & Species & $\mathbf{N}$ & $\mathbf{n}(+)$ & $\%$ \\
\hline EB-10-V & 2018 & 2010 & E. chaffeensis & Chisanga & Zambia & Africa & RLB & Bovinae & 38 & 0 & 0 \\
\hline EB-05-RYT & 2016 & $2007-2013$ & E. ruminantium & Bionzhou, Shandong & China & Asia & PCR & Bos taurus & 33 & 0 & 0 \\
\hline EB-05-HFG & 2016 & $2007-2013$ & E. ruminantium & Yancheng, Jiangsu & China & Asia & PCR & Bubalus & 29 & 0 & 0 \\
\hline EB-02-S & 2017 & 2015 & E. ruminantium & Kpinnou & Benin & Africa & $\mathrm{nPCR}$ & Bovinae & 20 & 0 & 0 \\
\hline EB-06-J & 2011 & 2009 & E. ruminantium & Bwabwata West & Namibia & Africa & PCR & Bovinae & 18 & 0 & 0 \\
\hline EB-47-QW & 2013 & 2013 & Ehrlichia spp. & & Sudafrica & Africa & PCR & Bovinae & 15 & 0 & 0 \\
\hline EB-10-X & 2018 & 2010 & E. ruminantium & Mungwi central & Zambia & Africa & RLB & Bovinae & 14 & 0 & 0 \\
\hline EB-10-Y & 2018 & 2010 & E. canis & Mungwi central & Zambia & Africa & RLB & Bovinae & 14 & 0 & 0 \\
\hline EB-10-Z & 2018 & 2010 & E. chaffeensis & Mungwi central & Zambia & Africa & RLB & Bovinae & 14 & 0 & 0 \\
\hline EB-06-TUI & 2011 & 2009 & E. ruminantium & Eastern flood plains & Namibia & Africa & PCR & Bovinae & 13 & 0 & 0 \\
\hline EB-06-CC & 2011 & 2009 & E. ruminantium & Mudumu & Namibia & Africa & PCR & Bovinae & 12 & 0 & 0 \\
\hline
\end{tabular}

